\title{
Postmodern Response to Multiculturalism in Higher Education
}

\author{
Christina Gramatikova \\ ${ }^{I}$ (College of Education, San Diego State University, United States)
}

\begin{abstract}
This is a conceptual paper to study artificial multicultural representations in higher education through French theorist Jean Baudrillard's postmodernist perspective. The study reviews literature and summarizes the evidence that higher education institutions are complicit in creation of hyperreality through multicultural misrepresentations in relationship to educational inequalities. The evidence outlined in the paper is analyzed using the postmodernist critical framework. Postmodernism refers to an emerging social reality, and focuses on cultural rather than economic or structural features (Kando, 1996). The framework is appropriate for this inquiry because it allows the reader to understand societal symbolic exchange and simulacra in terms of a counterfeit democracy in higher education, specifically addressing multiculturalism. The findings of the paper include different levels of hyperreality in higher education observed through quantitative data misrepresentation, ideological reproduction in higher education, as viewed from a Critical Race Theory (CRT) perspective, and the elusive quest for justice in democratic educational practice. The literature supports the conclusion that to truly counter educational disparities, the we must remove the limiting boundaries of conventionally perceived reality. The paper ends with recommendations for future research on higher education diversity measurement reviews. These measures must either be tailored to specific multicultural contexts, or otherwise must be sufficiently robust to be applicable across populations of students, faculty, and researchers.
\end{abstract}

Keywords: Multiculturalism, Critical Race Theory (CRT), Hyperreality

\section{Problem Statement}

\section{Introduction}

Although previous literature has addressed postmodernism in relation to multiculturalism, political and sociocultural constructions as nurtured by capitalism, few have reconceptualized multicultural education through French theorist Jean Baudrillard's postmodernist perspective. Moser (2015) illustrates in Baudrillard's terms that society exchanges signs in an effort to live the simulations that these social codes represent, perpetuating a divide - so long as something looks to be real, it does not matter what is actually happening. It is this abstraction that has founded a system of social control and power (Baudrillard \& Maclean, 1985). In relationship to this context, "multiculturalism seeks to promote the valuing of diversity and equal opportunity for all people through understanding" of perspectives of people of differing race, ethnicity, culture, language, religion and gender. (Wlodkowski \& Ginsberg, 1995, p. 36)

Prior research insufficiently explores postmodernist resources such as deconstruction of the role of power and discourse in relationship to multiculturalism in higher education and the concept of the "simulacrum" which can be defined an unsatisfactory imitation or substitute. Multicultural education applied through a postmodernist lens addresses the artificiality of equity outcomes for minority students, as higher education is a product of hegemonic capitalist economy. Zou and Trueba (2002) suggest:

The key to counter hegemonic cultural research involves: 1) the ability to link the production of representations, images, and signs of hyperrreality to power in the political economy and 2) the capacity, once the linkage is exposed and described, to delineate the highly complex effects of the reception of these images and signs on individuals located at various race, class, gender and sexual coordinates in the web of reality. (p. 95)

Fitting into this symbolic exchange is the consumer model of education and the perception of realized value for all students. In 2016, the higher education industry consisting of public and private universities offering baccalaureate or graduate degrees in the U.S., is expected to reach $\$ 550.3$ billion in revenue, and the number of college students is anticipated to increase to 22.2 million through 2021 (McCormack, 2016). IBISWorld reports that minority students have increased as a share of total students from 2009-2014 (McCormack, 2016). While California public colleges are generating $13.7 \%$ of the revenue produced by public universities nationwide (McCormack, 2016), educational opportunities and outcomes remain fractured for historically underrepresented students. Thus, the commoditizing of higher education creates a hyperreality, the inability to distinguish reality from simulation of reality, and floating values (Baudrillard, 1988). Not all students who obtain credentials, regardless of cultural background or socioeconomic group, are able to actualize the economic benefits of higher education. Since the primary focus is attracting a greater number of graduates, rather than the widening participation or achievement gap, social inequalities are reproduced. 
As higher education is deployed in a consumer driven environment, it is critical to question whether institutions are gaining the same pedagogical power corporations and media assert in the form of advertising (Zou and Trueba, 2002) through one-way dissemination of information "symbolic exchange", and how misrepresented data "simulacra" can be identified. Both ideological and data-driven concerns inspire the need for analysis of the conceptual problem. The consequences of not addressing differences in equity outcomes for minority student subgroups in a higher education setting, are limited institutional equity indicators and metrics, as well as the inability to assess institutional diversity performance.

This conceptual paper is intended to identify and understand the ideological reproduction in higher education as viewed from a critical postmodernist frame. The focus of this research is to address the disparity between represented educational equity for students of color in higher education, and the actual intrainstitutional stratification which remains largely invisible (Bensimon, 2004). This is important because it is unknown whether higher educational institutions continuously track and manage concrete measurements of multicultural diversity such as: access and composition (students, administrators, faculty, part-time faculty, engagement, inclusion, recruitment, retention, degree attainment, campus climate (receptivity to diversity), management of diversity, and dealing with tensions and social justice. These questions are beyond the scope of this present paper, but certainly warrant the attention of researchers.

\section{Purpose of Inquiry and Inquiry Questions}

Educational researchers have long been concerned with achievement, enrollment, and high school dropout rates (Paik \& Walberg, 2008) for non-White racial and ethnic groups. "Limited English mastery, economic hardships and cultural barriers" (Paik \& Walberg, 2008, p. 6) are also present in postsecondary education. Like Bensimon (2005), I extend this idea to higher education institutions, instead through a critical postmodernist conceptual framework. Ladson-Billings (2004) compares representations of multicultural America in elementary and secondary school. Similarly, I find these representations in the ways "dominant ideologies appropriate multicultural discourse" in higher education (Ladson-Billings, 2004, p. 52).

Pang (2011) and Goodwin (2010) present evidence which indicates minority student equity outcomes are often interpreted as aggregate statistics, and demonstrate the dangers of exclusion and stereotyping in relationship to inadequate data. These data indicate the ethnic heterogeneity of Asian American and Pacific Islander (AAPI) students, and the community overall. However, the active attempt to make meaning out of otherwise disembodied statistics can be applied to many other arenas where institutions must change (Bensimon, 2004).

Since wealth is a source of social and political power, the wealth gap issue is as concerning as the achievement gap (Ladson-Billings, 2006). This economic component is one way in which dominant groups exploit subordinate groups; the latter are the consumers of education and receptive to dominant narratives and texts. Baudrillard (1988) contends that the political economy and the law of commodity create symbolic counterfeit production. Perceptions of knowledge become blurred until the manufactured reality of higher education becomes hyperreal. Hyperreality governs higher education institutions and their representations of multiculturalism.

This conceptual paper is intended to identify, deconstruct and understand the aspects of production of representations and signs of hyperreality in higher education through critical postmodern approach. Therefore, the inquiry questions for this paper are:

1. Through analysis of multicultural education literature, what are common elements of multicultural production of representations and signs of hyperreality in a higher education intuition setting?

The answer to the inquiry question will be based on an extended review of literature as well as examples of multicultural diversity dimensions.

\section{A Conceptual Framework For Research}

Attracted by the intersection of current multicultural educational research theories, as well as the postmodernist concept as a critical practice, I began to see how literature revealed that discussions within multicultural education can be observed through Baudrillard's concepts of hyperreality, symbolic exchange and simulacra. In learning to interpret data through the theoretical critical postmodernist lens, I consciously focused on how symbolic representations of multiculturalism in higher education are perpetuating an "ever-widening chasm of inequalities" (Ochoa, 2003, p. 3).

As with all research, I am very much a part of what is represented here. As someone who is employed by and traditionally conditioned by a higher education institution, I have not completely adopted a critical postmodernist approach uncritically. Despite the rhetoric to the contrary, there is evidence of a voice of logical linearity creeping into the assessment informed by this theory through my European vantagepoint. By including this background and by articulating my approach and possible biases, I hope to offer enough information about what I intend to research, so that it may be understood in its fullest context. 


\section{Topical Research and Theoretical Framework}

America's political and economic systems are being transformed into a postmodern culture, in which imitations of imitations (i.e. simulacra) dominate and structure our lives (Freie, 2012) through one-way symbolic power exchange. This imitation pattern has been replicated in higher education, as evidenced by specious social and racial equality. There exists a seeming potential that benefits of higher education are available and beneficial to all, despite a growing disparity of wealth and declining literacy rates. In this short essay, I show that misrepresentation of multiculturalism in higher education can be understood through examining signs of hyperreality. While multicultural education has informed my thinking, I have taken a different theoretical track by fusing philosophical postmodernist theory with examination of the multiple dimensions of multicultural diversity.

Existing theoretical research and empirical work through the critical theory postmodernist lens has focused on the simulacra in feminist theory, political science, widening participation in higher education, and structural homogeneity among higher education institutions. Atkinson (2008) combines organizational theory with semiotic and discourse analysis to arrive at the conclusion that bureaucracy in higher education is so powerful that state of power is difficult to reverse which results "homogeneity in structure, culture and output" (p. 28). It can be inferred from his findings that the recruitment symbols used by higher education institutions are elitist in nature and follow a "pattern of consumerism" without much regard for students from different backgrounds, class structures, and histories (p. 42). On the topic of hyperreality, Holligan \& Chiang (2011) argue that student consumerism of higher education is characterized by end products - credentials, coupled with "edutainment", creating a duplicitous appearance signifying "deeply compromised knowledge" (Holligan \& Chiang, 2011, p. 241). The methodological basis employed by Holligan \& Chiang includes a of critical examination of the paradigm of public sector universities from the perspective of French postmodernist theory, of which the notions of hyperreality developed by Jean Baudrillard are utilized. Both studies comment of the imminent class fragmentation which will result from higher education institutions' attempts capture markets to safeguard their income streams.

Few studies have combined similar analyses of elements of societal symbolic exchange and simulacra in terms a counterfeit democracy in higher education specifically addressing multiculturalism. Therefore, a comprehensive understanding of this approach can be achieved through a review of multicultural education literature and current examples in higher education. The exploration of the relationships between the cultural, symbolic, linguistic and material interactions in higher education is represented in Figure 1, and this framework represents an ideological reproduction.

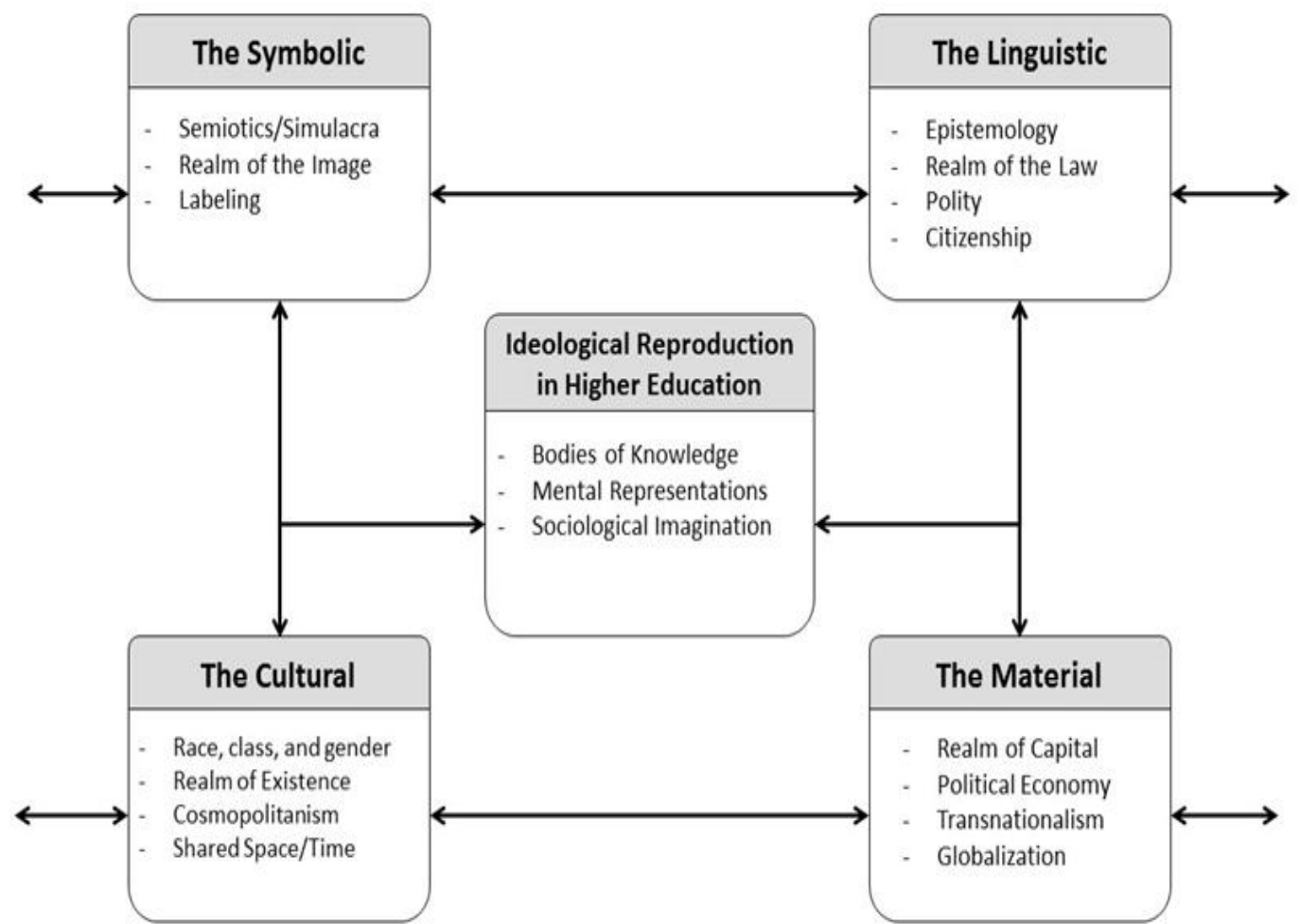

Figure 1. Cultural, Symbolic, Linguistic and Material Interactions in Higher Education

Source: Adapted from "Economic Nomads: A Theoretical Deconstruction of the Immigration Debacle," by Brian G. Sellers and Bruce A. Arrigo, 2016, Journal of Philosophical \& Theoretical Criminology, 8, p. 40. 
The methodological approaches that inform the topic are critical theory, Baudrillard's classifications of postmodernism alongside philosophical foundations of Marxian tradition. The proposed framework incorporates other significant components that developed from postmodernist theorists Jacques Derrida and Michel Foucault. Derrida's work consisted of linguistic deconstruction of other scholars' texts, and Foucault examined and critiqued historical institutional arrangements (Kando, 1996).

The worth of research interpreted in this framework, is that it offers educational scholars a means of understanding the falseness of representations and ideological reproductions. In recognizing the imitation of a democratic education, educators and scholars can attempt to dismantle "the existing money making schemes of entrance exams, challenge and transform curriculum to include diversity in learning styles such as multiple intelligences" (Ochoa, 2003, p. 4). Both educators and scholars can benefit from this knowledge to renegotiate the power balance in their educational institutions. Multicultural education scholars can thus see how to challenge the structures that have positioned them. To achieve a conflation of conceptual theoretical models, I will first introduce the theory of hyperreality, symbolic exchange and simulacra as it has been defined in the works of Jean Baudrillard (Sichler, 2010). Next, I will trace the trajectory upon which multicultural education has traveled in within this framework. What follows is a brief discussion of the major characteristics of production of representations and signs of hyperreality.

\section{Literature Review}

\section{Limitations}

Several elements delimit this conceptual paper. First, this paper reviews the symbolic, cultural, linguistic, material misrepresentations in higher education as evidence of a postmodern cultural transformation only through multicultural education standpoint. This is delimiting because it excludes conceptual illustrations in K-12 education, and other elements of postmodernity in education. Second, the theoretical framework uses the notion of the levels of hyperreality and symbolic exchange produced in our postmodernist culture, as conceived by Jean Baudrillard. This is delimiting because the characteristics can be much more broadly applied to critical interpretations of Western culture, politics, and economics. This conceptual paper also has analytical restraints. For example, it relies on data previously collected by other researchers because of the inability to collect data and review full depth and breadth of literature due to time constraints.

\section{Analysis and Discussion of the Literature}

This section will explore the levels of hyperreality in higher education through discussion of quantitative data misrepresentation, ideological reproduction in higher education, as viewed from a Critical Race Theory (CRT) perspective, and the elusive quest for justice in democratic educational practice. Key factors that influence multicultural education will be explored using the postmodernist lens. The implications of the literature will be summarized, and will include a presentation and discussion of the theoretical framework.

\section{Literature depicting "Hyperreality" in Higher Education}

Through Baudrillard's postmodernist representation of hyperreality there exist four stages of understanding: counterfeit, production, simulation, and virtual (Sichler, 2010). By the virtue of the examples which will be discussed, only the first three stages will be examined. The concept of simulacra through a multicultural perspective in higher education has not been addressed in literature. Counterfeit, the first stage of hyperreality, can be understood through misrepresented diversity outcomes metrics in higher education institutions signal illusive, not actual equity of outcomes among diverse student populations. Therefore, I will examine multicultural representations and lack of correspondence between metrics i.e. symbols, and meaning in higher education for evidence of fakeness or embellishment of truth. Production, the second stage of hyperreality, becomes apparent when exploring the isomorphism and ideological reproductions in higher education institutions. Simulation, the third stage of hyperreality, produces a reality of its own. It is established in relations which domination persist on their own, and are replicated in everyday white discourse. Sleeter (1995) as cited by (Moon, 1999) contends that:

In discussing issues of race, white people frequently shift linguistically into a kind of "white code" that permits them to talk about race-related matters in ways that "render the status quo "natural,' remove ourselves from complicity, and secure approval from other whites." (p. 188)

The status quo is replicated through superficial language, and these euphemisms and hyper-politeness are rooted in simulacra. Although previous literature has addressed hyperreality and simulacra in politics and educational research, relatively little work has explicitly addressed levels of hyperreality through a multicultural education perspective. The discussion of the duplicitous higher education multicultural paradigm is the focus of this conceptual paper. The implications of hyperreality through the first three levels, counterfeit, production and simulation will be discussed here through ongoing challenges which affect higher education institutions. These examples will trace the interactions between Baudrillard's orders of hyperreality: counterfeit, production, and simulation. 


\section{The Diversity Scorecard: Institutional Research Statistics}

First order: counterfeit. Prior quantitative work has revealed that "intra-institutional stratification based on race and ethnicity is a reality at most of the nation's colleges and universities" (Bensimon, 2004, p. 46) and that overall institutional research statistics do not shed light on the reality of undemocratic educational outcomes. Institutional accountability requirements do not require detailed statistics other than actual numbers reflecting admitted or enrolled minority students. For example, overall academic and major enrollments, "term-to-term and year-to-year persistence rates, and GPA distributions" (Bensimon, 2004, p. 48) are regularly reported. This research establishes that there is not a lack of institutional data on race, ethnicity and inequitable outcomes in colleges and universities, but an excess.

The Diversity Scorecard research team (Bensimon, 2004) found that most of the participating higher education institutions thought they had already achieved an initial stage of diversity, since they had achieved a student body which was "racially and ethnically diverse on a statistical basis" (Bensimon, 2004, p. 48). These institutions saw no need to disaggregate their data further. In one case disaggregating the data revealed highly political information about minority students, which the institution chose not to pursue. Another case exposed a resistance to investigate ethnic fragmentation, and as one dean stated "we are 100 percent diverse...for us there are no differences by ethnicity" (Bensimon, 2004, p. 48).

This is one example of democratic manipulation through which compounded primary data represent consumerist symbols, and take the place of reality and authentic understanding (Moser, 2015). Aggregated statistical observations represent the social exchange of commercial representations that in some cases are devoid of any real significance. Baudrillard warns against the dangers of the proliferation of inauthentic, representation of success which bombard us, and the Diversity Scorecard study reveals one facet of contradictory facts and institutional tendencies which serve to mislead. Although the Diversity Scorecard research has addressed remedial education metrics by race and ethnicity to help higher education campuses assess their effectiveness, further research should present larger samples across broader geographic areas and analysis of the implications if similar results are generalizable to other organizations.

\section{Institutional Isomorphism and Intertextuality}

Second order: production. Given that the U.S. educational system operates primarily from the structural functionalism and assimilationist sociological mode (Ochoa, 2003), can higher education operate outside of the realm of reproduction of multicultural imitations? Atkinson (2008) explored the elements of corporate identity in homogeneity, culture and output of higher education institutions (HEIs). The study randomly sampled twenty-eight Carnegie Research Intensive institutions to analyze mission statements, web sites and images of the organization to determine patterns of homogeneity. The Carnegie system definition of a Research-Intensive university includes a strong graduate program, one that has awarded "at least ten doctoral degrees per year across three or more disciplines, or at least 20 doctoral degrees per year overall" (Atkinson, 2008, p. 31). The findings indicated that these HEIs exhibited intertextuality and isomorphism related to mission statements, slogans, and seals. One of the findings illustrated symbolic reference of students in a global setting, global marketplace and community. The simulated student imagery provides compelling rationale of the university as a hyperreal setting, since institutions tend to copy one another in their depiction of a global and diverse student body. Furthermore, such surface imagery indicates an ambiguous connection to reality - simulacra which serves to conceal.

Can all students take advantage of the "global" cultural and societal perceived benefits which universities proliferate? The article provided no specific information or findings as related to the realities which emerge from exclusion. One possible simulation which could be further investigated and exposed in relationship to different types of HEI isomorphism is the critical race theory (CRT) perspective. CRT has postmodern threads and rely "on the importance of perspective and context in assessing truth claims (Parker \& Lynn, 2009, p. 152). The critical race theorists seek to break down the dominance of storytelling "about success, merit, equality, the market and objectivity that is so deeply entrenched and accepted unquestioningly by larger society" (Parker \& Lynn, 2009, p. 152).

\section{The Challenging Landscape for Opportunity and Equity}

Third order: simulation. Higher education is still a system of one-sided advantage, therefore simulation of equal educational opportunity is the dominant order of the present phase of history (Baudrillard \& Poster, 1988). An example of this is the unevolved promise of civil rights legislation. Yosso, Parker, Solórzano, and Lynn (2004) claim that opponents of affirmative action usurp civil rights language and ignore the historical and present-day realities of communities of color. The ensuing argument is that factoring race in higher education discriminates against Whites. As a result, the subordination of civil rights interests is maintained, and White privilege upheld. Without a basis in the histories and lived experiences of students of color, the present system reproduces itself and remains a perpetual simulation of equality. Ladson-Billings (2009) confirms this fact, in 
1991 only $3.8 \%$ of doctorate degrees awarded went to African American men and women, and 20 years after affirmative action, "African Americans constitute only 4.5\% of the professorate" and (Ladson-Billings, 2009, p. 22).

The continuing battle for affirmative action in higher education includes: Hopwood v. University of Texas Law School (1996); Grutter v. Bollinger and Gratz v. Bollinger (2003); the University of Georgia's Affirmative Action admissions program; Michigan voters' approval of Proposition 2; the U.S. Supreme Court ruling upholding the right of voters in Michigan to ban race-sensitive admissions at state-operated colleges and universities (King, 2016, p. 168). These cases and civil rights initiatives illustrate anti-affirmative action threats which will potentially increase the current inequalities based on class, gender, and racial divisions. Privileged groups still have more immediate access to higher education. It is therefore our challenge to create and deliver access, composition, inclusion, recruitment, and retention measures in order to overcome some of the divisions and inequalities that have plagued the educational landscape.

\section{Findings From Literature}

The literature and theoretical framework was useful for understanding the topic for this conceptual paper and enabled me to answer the main inquiry question.

\section{Inqiuiry question:}

Through analysis of multicultural education literature, what are common elements of multicultural production of representations and signs of hyperreality in a higher education intuition setting?

\section{Finding 1:}

The common elements of representations as assessed through a schematic understanding hyperreality, are counterfeit diversity metrics, reproduction of multicultural imitations, and simulated democratic outcomes relative to affirmative action efforts.

The consequences of educational inequities are greatest for marginalized minority and disadvantaged students. To monitor and assess the success of the increasing attempts to improve educational equity across the nation, a more comprehensive array of valid measures are needed. Unfortunately, measurement in the area of improving educational equity has lagged, hindering our ability to assess these efforts. Valid and reliable measures of the many facets educational inequities, which are broadly-accepted and distributed, used in a consistent manner to assess change across monitoring and evaluation studies, will significantly advance national efforts.

\section{Conclusion}

Higher education institutions play a foundational role in critical development and identity formation for adolescents, thus the impact of diversity on learning and equity outcomes is particularly important during the college years (P. Gurin, Dey, Hurtado, \& G. Gurin, 2002). Educational inequities elucidated by counterfeit diversity metrics, reproduction of multicultural imitations, and undeveloped affirmative action efforts compromise nationwide development. Gurin et. al (2002) corroborate this perspective by citing Justice Lewis Powell from the affirmative action case Regents of the University of California v. Bakke, U.S. Supreme Court (1978) Justice Powell argues that the:

Atmosphere of 'speculation, experiment and creation' - so essential to the quality of higher education is widely believed to be promoted by a diverse student body... It is not too much to say that the nation's future depends upon leaders trained through wide exposure to the ideas and mores of students as diverse as this Nation of many peoples. (p. 331)

In alignment with this perspective, and to truly counter educational disparities, we must remove the limiting boundaries of conventionally perceived reality. Thus, the elements of multicultural representations and constructs of hyperreality can be applied through the postmodernist frame to assess educational democratic outcomes.

\section{Recommendations for Future Research}

Measurable constructs should be identified based on social, behavioral science theories and existing conceptual frameworks focused on development of multicultural equity outcomes. Evidence reviews and a building of consensus on gaps in equity outcomes are needed to advance research on multiculturalism in higher education. These measures must either be tailored to specific multicultural contexts, or otherwise must be sufficiently robust to be applicable across populations of students, faculty and researchers. Cross-population measures, while not always possible, allow for broader and more inclusive statements to be made on the educational inequities that span across the U.S. Higher education diversity measurement reviews, affirmative 
action policy development and improvement can support higher quality data through which educational equity programs, policies and targets can be monitored and evaluated.

\section{References}

[1]. Kando, T. (1996). Postmodernism: old wine in new bottles? International Journal on World Peace, 13(3), 3-33.

[2]. Moser, K. (2015). Deconstructing consumerist signs in an era of information: The post-semiotic philosophy of michel serres and jean baudrillard. Pennsylvania Literary Journal, 7(3), 94-122, 211.

[3]. Baudrillard, J., \& Maclean, M. (1985). The Masses: The Implosion of the Social in the Media. New Literary History, 16(3), 577589. doi:1. Retrieved from http://www.jstor.org/stable/468841 doi:1

[4]. Wlodkowski, R. J., \& Ginsberg, M. B. (1995). Diversity \& motivation: culturally responsive teaching. jossey-bass higher and adult education series. jossey-bass Education series, jossey-bass social and behavioral science series. Jossey-Bass Inc., 350 Sansome St., San Francisco, CA 94104.

[5]. Zou, Y., \& Trueba, E. T. (2002). Ethnography and schools: qualitative approaches to the study of education. Rowman \& Littlefield Publishers

[6]. McCormack, R. (2011). Colleges \& universities in the US. IBISWorld Industry Report 61131a. Retrieved from IBISWorld database.

[7]. Baudrillard, J., \& Poster, M. (1988). Selected writings. Stanford, CA: Stanford University Press.

[8]. Bensimon, E. (2004). The diversity scorecard. Change, 36(1), 44-52.

[9]. Paik, S. \& Walberg, H. (Eds.) (2008). Narrowing the achievement gap: strategies for educating latino, black, and asian students. New York: Springer.

[10]. Bensimon, E. M. (2005). Closing the achievement gap in higher education: An organizational learning perspective. New Directions for Higher Education, 131, 99-111.

[11]. Ladson-Billings, G. (2004). New directions in multicultural education. Handbook of research on multicultural education, $2,50-65$.

[12]. Pang, V. O., Han, P. P., \& Pang, J. M. (2011). Asian American and Pacific Islander students: Equity and the achievement gap. Educational Researcher, 40, 378-389.

[13]. Goodwin, A.L. (2010). Curriculum as colonizer (Asian) American education in the current U.S. context. Teachers College Record, $112,12,3102-3138$.

[14]. Ladson-Billings, G. (2006). From the Achievement Gap to the Education Debt: Understanding Achievement in U.S. Schools. Educational Researcher, 35(7), 3-12. Retrieved from http://www.jstor.org/stable/3876731

[15]. Ochoa, A. (2003). The Ochoa Paradigm: Models of cultural pluralism. Unpublished Manuscript.

[16]. Freie, J. F. (2012). Postmodern Politics in America. Society, 49(4), 323-327. doi:10.1007/s12115-012-9555-7

[17]. Atkinson, T. N. (2008). Imitation, intertextuality, and hyperreality in U.S. higher education. Semiotica, 169, 27-44. doi:10.1515/SEM.2008.023

[18]. Holligan, C., \& Chiang, K. (2011). Browne's Capgas Delusion: The Destruction of the Public University. Journal For Critical Education Policy Studies (JCEPS), 9(2), 241-259.

[19]. Sellers, B. G., \& Arrigo, B. A. (2016). Economic Nomads: A Theoretical Deconstruction of the Immigration Debacle. Journal of Philosophical \& Theoretical Criminology, 8(1), 37-56.

[20]. Sichler, K. (2010). Post queerness: Hyperreal gender and the end of the quest for origins. The Spectator, 30, 46-56. Retrieved from http://libproxy.sdsu.edu/login?url=http://search.proquest.com.libproxy.sdsu.edu/docview/310971322?accountid=13758

[21]. Moon, D. G. (1999). White enculturation and bourgeois ideology: The discursive production of "good (white) girls." In T. K. Nakayama \& J. N. Martin (Eds.), Whiteness: the social communication of identity (pp.177-197). Newbury Park, CA: Sage.

[22]. Parker, L. \& Lynn, M. (2009). What's race got to do with it? Critical Race Theory's conflicts with and connections to qualitative research methodology and epistemology. In D. Gilborn \& G. Ladson-Billings (Eds.), Foundations of critical race theory in education (pp. 148-161). New York: Routledge.

[23]. Yosso, T., Parker, L., Solórzano, D., \& Lynn, M. (2004). From Jim Crow to Affirmative Action and Back Again: A Critical Race Discussion of Racialized Rationales and Access to Higher Education. Review of Research in Education, 28, 1-25. Retrieved from http://www.jstor.org/stable/3568134

[24]. Ladson-Billings, G. (2009). Just What Is Critical Race Theory and What's It Doing in a Nice Field Like Education? In D. Gilborn \& G. Ladson-Billings (Eds.), Foundations of critical race theory in education (pp. 17-36). New York: Routledge.

[25]. King, J. E. (2016). We May Well Become Accomplices To Rear a Generation of Spectators Is Not to Educate at All. Educational Researcher, 45(2), 159-172.

[26]. Gurin, P., Dey, E. L., Hurtado, S., \& Gurin, G. (2002). Diversity and higher education: Theory and impact on educational outcomes. Harvard Educational Review, 32(3), 330-366. $\quad$ Retrieved http://libproxy.sdsu.edu/login?url=http://search.proquest.com.libproxy.sdsu.edu/docview/ 